\title{
Evaluating Effectiveness and Permanence of Selenium Treatment in a Solid Matrix via Aqueous-Mediated Zero Valent Iron Reaction
}

\author{
Scott A. Grieco*, Danielle C. Singer, Gary R. Bement \\ O’Brien \& Gere Engineers, Inc., Syracuse, New York, USA \\ Email: ^scott.grieco@obg.com
}

How to cite this paper: Grieco, S.A., Singer, D.C. and Bement, G.R. (2017) Evaluating Effectiveness and Permanence of Selenium Treatment in a Solid Matrix via Aqueous-Mediated Zero Valent Iron Reaction. Journal of Environmental Protection, 8, 990-1001.

https://doi.org/10.4236/jep.2017.89062

Received: June 21, 2017

Accepted: August 21, 2017

Published: August 24, 2017

Copyright $\odot 2017$ by authors and Scientific Research Publishing Inc. This work is licensed under the Creative Commons Attribution International License (CC BY 4.0).

http://creativecommons.org/licenses/by/4.0/ (c) $\underset{\mathrm{EY}}{0}$ Open Access

\begin{abstract}
Increasingly, as regulatory limits become more stringent, selenium has become a parameter of concern. Selenium is a naturally occurring element that is largely mobilized by anthropogenic activity such as mining for fuel and subsequent combustion, metal ore refining and processing, and agricultural irrigation. Of concern is removing selenium liquid matrices and immobilizing it from leachable solid matrices. Chemical reduction and stabilization using zero valent iron (ZVI) is applicable to both concerns. The solid matrix case study is applicable to ash ponds solids or industrial bag house dust solids. This paper presents data for treatment and stabilization of selenium within a solid matrix using ZVI. The methodology uses an aqueous mediate reaction to promote a stable solid matrix of non-leachable selenium. The paper describes matrix challenges and key variables that effected successful treatment. Testing with simulated and real bag house dust solids were used to establish data to support the permeance of the reaction. The data show that ZVI converts ionic selenium to a zero valent state in the solid matrix. It was also recognized that a fraction of ionic selenium may fail to react with the ZVI, but the results show that despite the presence of the unreacted ionic selenium, the toxicity characteristic leachate procedure (TCLP) results following treatment do not exceed the $1 \mathrm{mg} / \mathrm{L}$ hazardous waste criteria.
\end{abstract}

\section{Keywords}

Bag House Dust, Selenium, Chemical Reduction, Land Disposal Restrictions, Toxicity Characteristic Leaching Procedure, TCLP, Zero Valent Iron 


\section{Introduction}

Increasingly, as regulatory limits become more stringent, selenium has become a parameter of concern. Selenium is a naturally occurring element that is largely mobilized by anthropogenic activity such as mining for fuel and subsequent combustion, metal ore refining and processing, and agricultural irrigation [1] [2]. Selenium, despite being an essential trace element needed by all organisms, is if concern in larger concentrations due to its potential to bioaccumulate which can result in toxic effects [3].

One particular concern is immobilizing selenium contained in a solid waste material prior to disposal. The environmental fate of selenium is closely linked to it redox state, as the oxyanions selenite $\left(\mathrm{Se}^{4+}\right)$ and selenate $\left(\mathrm{Se}^{6+}\right)$ are mobile and relatively poorly adsorbed on natural solids [4]. Selenite and selenate are more readily bioavailable and pose a greater toxic risk than elemental selenium [5]. It has been seen that selenium is leached from solids such as baghouse dust (BHD) from aluminum processing when analyzed using the Toxicity Characteristic Leachate Procedure (TCLP) (USEPA Method 1311). Chemical reduction and stabilization using zero valent iron (ZVI) was considered for a BHD containing selenium at concentrations that caused the solid matrix to exceed characteristically a $1 \mathrm{mg} / \mathrm{L}$ TCLP hazardous thresholds (USEPA, 40 CFR 261.24). Under this program, an approach was developed which utilized ZVI with BHD in a water-phase promoted chemical reduction and surface adsorption reaction.

The motivation for this research was regarding United States Environmental Protection Agency (USEPA) Land Disposal Restrictions (LDR) Phase IV: Final Rule Promulgating Treatment Standards for Metals Wastes and Mineral Processing Wastes [6]. This standard documents that addition of iron metal, in the form of fines, filings, or dust, for the purpose of ostensibly achieving a treatment standard for lead in foundry sands is "impermissible dilution" [6]. An interpretation of this ruling by a non-federal agency regards use of ZVI to treat metals other than lead in matrices other than foundry sands as "impermissible dilution." This contrasts with the argument that addition of ZVI constitutes treatment when the iron metal is an integral reagent for chemical reaction and stabilization (e.g., efficacy of treatment). Concerns regarding the long-term stability of selenium in the BHD subsequent to disposal in a landfill were also expressed (e.g., permanence of treatment).

This paper presents bench-scale stabilization testing conducted and describes the methods and results of the simulated landfill stabilization testing. The objective was to demonstrate the efficacy and permanence of treatment with respect to selenium-ZVI treatment in a BHD matrix. This treatment has been the focus of many other studies with positive results for selenium decontamination including agricultural drainage water and ash pond water from a coal-fired power plant [7] [8].

At low concentrations of selenium in water, selenium is removed through surface adsorption and chemical reduction [9] [10]. The reaction mechanism is as follows [9]: 


$$
\begin{gathered}
\mathrm{Fe}_{0} \Leftrightarrow \mathrm{Fe}^{2+}+2 \mathrm{e}^{-} \quad E_{0}=-0.41 \mathrm{~V} \\
\mathrm{HSeO}_{4}^{-}+3 \mathrm{H}^{+}+2 \mathrm{e}^{-} \Leftrightarrow \mathrm{H}_{2} \mathrm{SeO}_{3}+\mathrm{H}_{2} \mathrm{O} \quad E_{0}=-1.15 \mathrm{~V} \\
\mathrm{H}_{2} \mathrm{SeO}_{3}+4 \mathrm{H}^{+}+4 \mathrm{e}^{-} \Leftrightarrow \mathrm{Se}_{0}+3 \mathrm{H}_{2} \mathrm{O} \quad E_{0}=-0.74 \mathrm{~V}
\end{gathered}
$$

The standard reduction potentials of Reactions 2 and 3 are higher than Reaction 1, indicating that selenate can be reduced to elemental selenium $\left(\mathrm{Se}_{0}\right)$ by ID $\left(\mathrm{Fe}_{0}\right)$ under standard conditions [11]. Recent work by Ling has demonstrated through advanced microscopy and analysis that that chemical reduction of $\mathrm{Se}^{+4}$ to $\mathrm{Se}^{0}$ is the main Se-ZVI reaction mechanism [12].

The form of selenium in the landfill will be dependent on the environmental conditions present. It is recognized that over time as the stabilization of the waste passes from aerobic to anaerobic to methanogenic, oxidation-reduction potential ( $p e$ ) decreases, indicating that the landfill will maintain a significant reducing environment [13]. As can be seen by the pe-pH diagram (Figure 1), the shaded rectangle represents a typical landfill environment (acidic $\mathrm{pH}$ and low pe) [11]. Within this environment, the selenium metal $\left(\mathrm{Se}^{0}\right)$ and selenide $\left(\mathrm{Se}^{2-}\right)$ will be stable and thus there exists limited potential for re-oxidation to selenate or selenite. In reducing conditions selenium solubility is low, but when the pe is above 3.38 the concentration of dissolved selenium increases significantly. Selenium solubility is at its maximum in oxidizing conditions at a $\mathrm{pH}$ of 6.5, with increasing solubility as pe increases [14]. Therefore, within a landfill environment, the selenium metal $\left(\mathrm{Se}^{0}\right)$ and selenide $\left(\mathrm{Se}^{2-}\right)$ should be stable and thus there exists limited potential for re-oxidation to selenate or selenite.

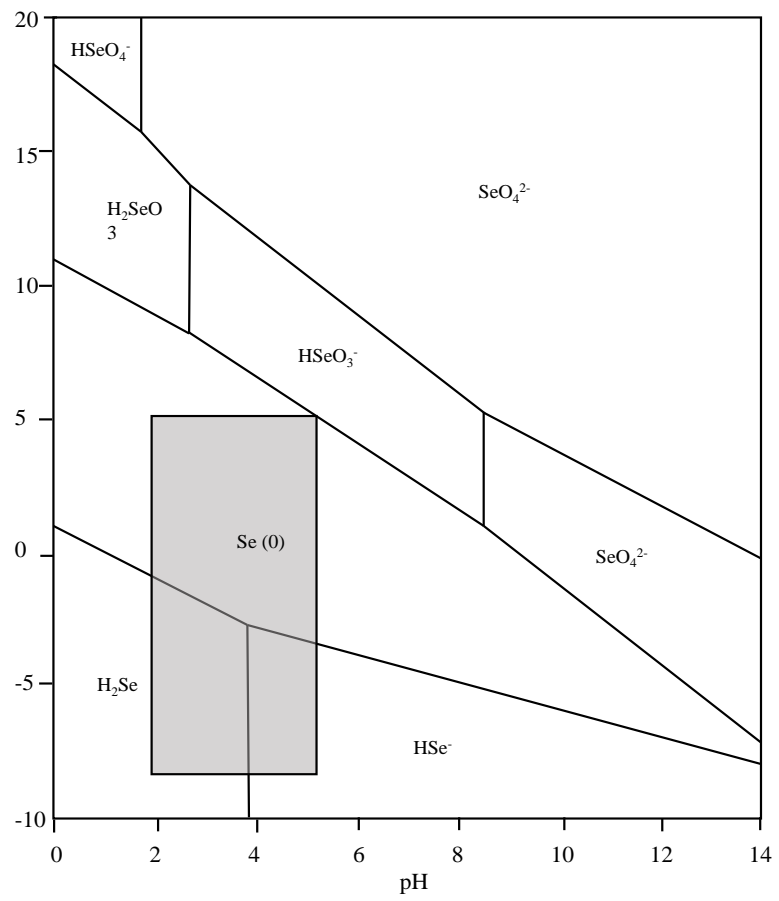

Figure 1. The pe vs $\mathrm{pH}$ for selenium and selenium containing compounds. The shaded box area indicates likely landfill conditions for both oxidation-reduction potential (pe) and $\mathrm{pH}[11]$. 


\section{Testing Materials and Analytical Procedures}

Reagent grade (Fisher Scientific, USA) and production grade zero valent iron (ZVI) were used for testing. Bag house dust (BHD) was provided by manufacturer in the aluminum industry. Deionized water was used for all aqueous additions to solid test aliquots. Analytical grade zero valent selenium (ZVS) and silica power (Sigma Aldrich, USA) were used to prepare simulated reacted and stabilized BHD.

Particle size distribution was conducted via sieve screening (ASTM C136). Samples used for treatment were mechanically agitated using a shaker table. Toxicity characteristic leaching procedure (TCLP) tests were conduct both in-house and using an external laboratory (EPA Method 1311) using Type I extraction solution. Aqueous phase selenium was quantified using ICP/AES (EPA Method 6010C). As noted in the results, certain samples were exposed to an intensive acid/microwave digestion procedure in lieu of standard EPA hot nitric acid digestion method.

\section{Methods and Results}

\subsection{Effect of ZVI Mass Ratio}

Several blends of BHD, ZVI, and water were selected for treatment. BHD and ZVI ratio blends tested include 96 BHD:4 ZVI, 92 BHD:8 ZVI ID and 90 BHD:10 ZVI. Ratios are mass based. The 96 BHD:4 ZVI was selected based on bench-scale screening tests for use in the remaining tests (data not shown).

\subsection{Effect of ZVI Particle Size}

In order to identify an effective and practical source of iron for larger-scale operation, a particle size distribution was performed with trial production grade, bulk production grade, and analytical grade iron dust. Particle sizes were screened between 20 and 400 mesh. Bulk production and analytical grades were found to be composed primarily of 100 to 400 mesh, approximately $70 \%-80 \%$ by mass. Whereas the trial production grade was coarser with $70 \%$ of the sample mass residing in the 20 to 40 mesh range.

Upon completing the particle size distribution, dusts of each incremental mesh size were used to quantify the efficacy of treating selenium in a BHD matrix. Results from this testing are shown in Figure 2. As expected, the removal efficiency per unit mass of iron added increased with smaller particle size, due to greater surface area available for reaction. Results from this testing show that iron dust particles of 80 mesh or smaller result in $90 \%$ reduction in selenium as detected by the TCLP test after treatment; iron dust of this size range was considered optimum for treatment.

\subsection{Effect of Water Ratio}

Because the selenium in the BHD needs to be solubilized and contacted with the ZVI surface, adequate water is required. However, water not only adds mass 
(and thus can increase the cost of disposal), but the requirements under 40 CFR 268.3 impose an upper limit of materials that can be added to comply with permissible dilution values (EPA, 1998). Five different mass fractions of water were added to aliquots of $96 \mathrm{BHD}: 4 \mathrm{ID}$, respectively. All samples were mechanically agitated until water and ZVI combined with the BHD. Figure 3 shows the selenium TCLP results as a function of water added.

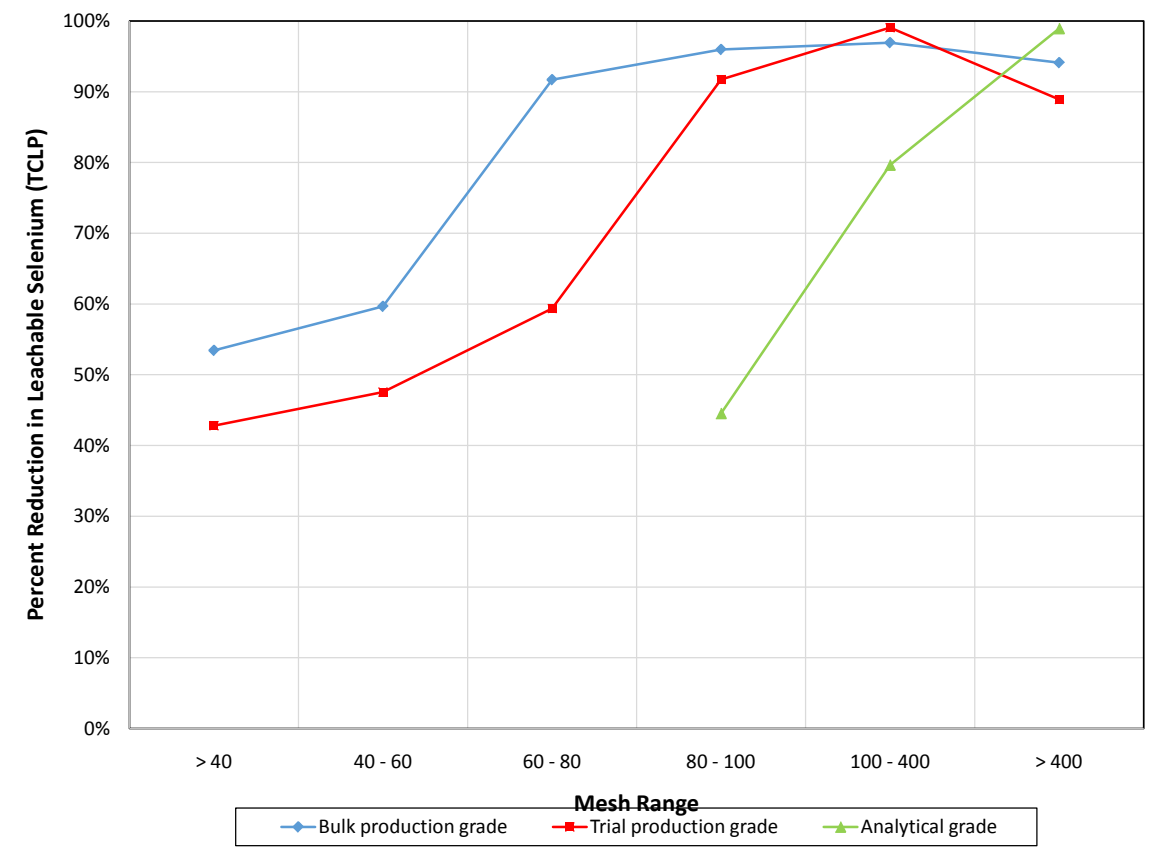

Figure 2. Reduction in TCLP selenium concentration as a function of ZVI particle size.

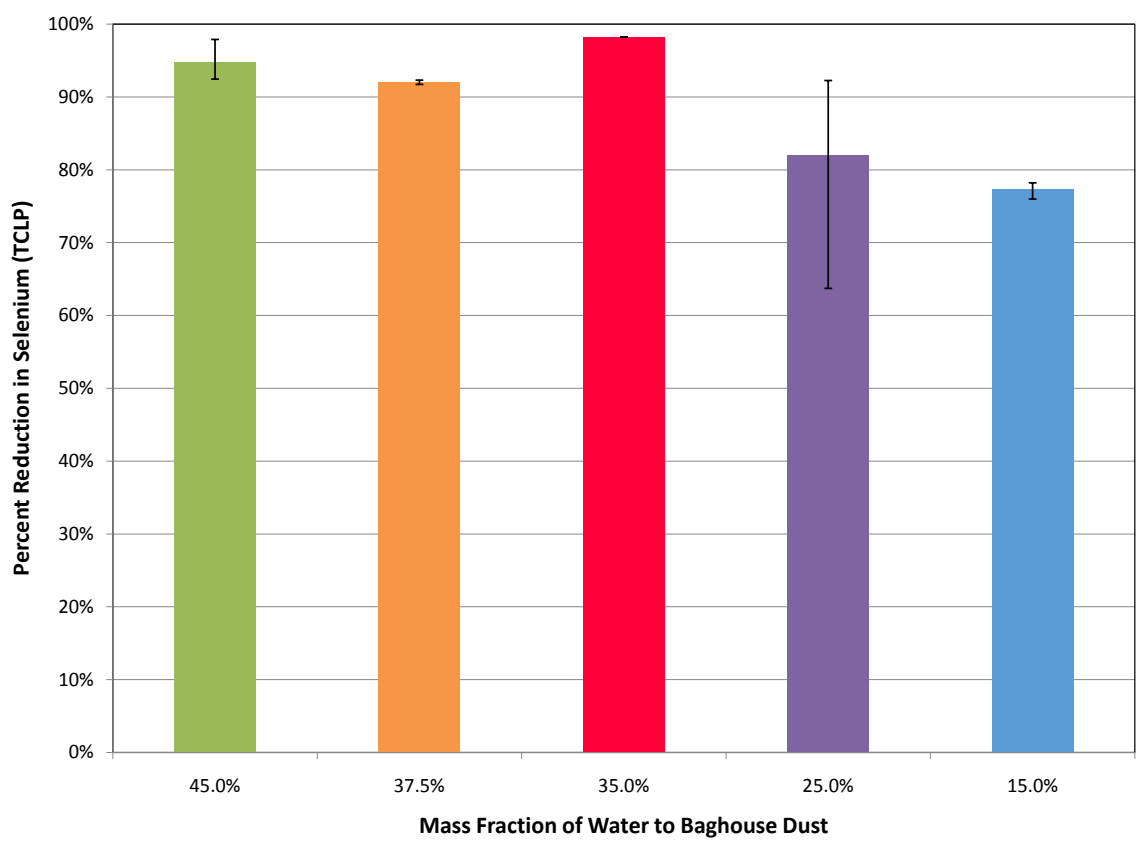

Figure 3. Observed selenium reduction in BHD blends with 96 BHD: 4 ID at varying mass fractions of water. Error bars indicate the range of values for replicate samples. 
The results of this testing demonstrate that selenium-containing BHD can be chemically stabilized with ZVI at an approximate 96 BHD: 4 ID ratio with 35\% water by mass, which is below the acceptable dilution ratio of 0.45 . Above $35 \%$, significant benefits were not observed. Below $35 \%$ water, the mass of water was insufficient to promote complete stabilization. This is because the selenium/iron oxidation-reduction reaction is a water-mediated reaction and the selenium must be dissolved and transported to the ZVI surface to occur.

\subsection{Effect of Cure Time}

During particle size distribution testing, TCLP tests were completed both in-house and using an external laboratory. Resulting selenium concentrations of TCLP from the external laboratory were consistently less than the in house TCLP extractions. It was recognized that samples sent to the external laboratory experienced approximately 3 days of time (transport and receiving) between treatment and commencement of analysis, whereas in house extractions began on the day treatment was performed. It was determined this transport time played a role in treatment efficiency. Therefore, additional testing was conducted utilizing treated material allowed to cure in open air for a time period of 3 and 10 days, respectively, to allow for the mechanism of treatment to take place.

Figure 4 shows TCLP values for BHD samples treated with water and ZVI for 0,3 , and 10 day cure times. The "Initial Se TCLP" (0 days cure time) shows the reduction in selenium by comparing TCLP values from the external laboratory, before and after treatment with ZVI and water. This sample would have been subjected to a 3 day cure as a result of transport. Improvement upon curing is

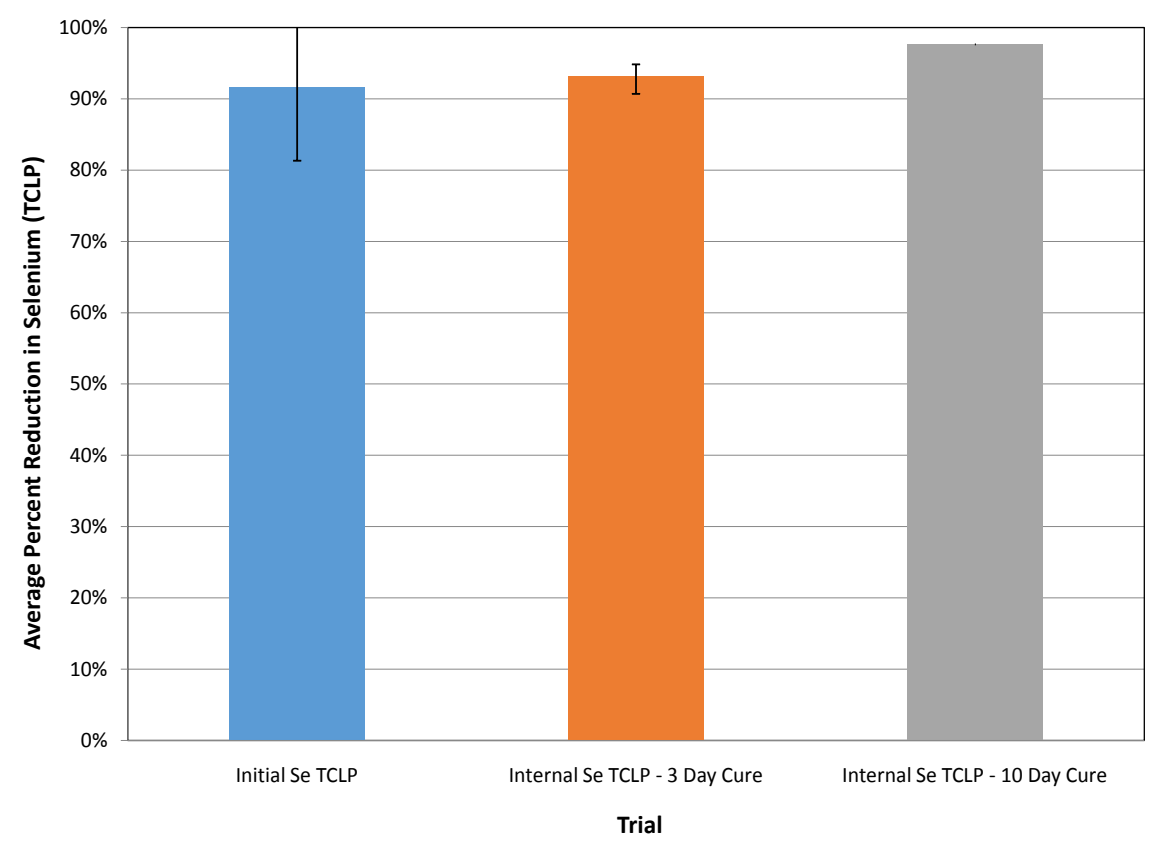

Figure 4. Average percent reduction in selenium TCLP. Error bars indicate the range of values for replicate samples. 
supported by increased average percent reduction in selenium TCLP values and minimization of data distribution of replicates (Figure 4 error bars). These data support the observations of data from the outside lab and suggest that a minimum 3 day cure time is necessary for optimized chemical stabilization.

\subsection{Longer-Term Static "Weathering" Tests}

Extended solids-phase extraction time periods were conducted on both 3 and 10 day cured samples. Treated samples of BHD were submerged in TCLP extraction fluid for periods of 1, 2, 3 and 4 and 13 weeks. Results from extended TCLP extractions are shown in Figure 5.

Average TCLP selenium concentrations of untreated BHD used in this phase of testing was $4.55 \mathrm{mg} / \mathrm{L}$ (range 4.39 to $4.71 \mathrm{mg} / \mathrm{L}$ ). The resulting selenium concentrations were less than the $1.0 \mathrm{mg} / \mathrm{L}$ limit for hazardous waste criteria. Samples cured for 3 days result in an average reduction of leachable selenium by $93 \%$. Samples cured for 10 days result in an average reduction of leachable selenium by $97 \%$.

Regarding the observable increase in dissolved selenium concentrations in the 3-day cured material, there are several possible explanations as to why concentrations increase between weeks 4 and 13. Individual samples were prepared in an identical manner in a single batch, except for the cure time of 3 or 10 days. The increase of dissolved selenium in 3 day cured samples beginning in week 4 may be a result of physical stability differences between the 3-day and 10-day cure samples. The shortened cure time may also not allow for adequate chemical stabilization, if some of the selenium is still present in aqueous solution which could be exposed during longer soak time.

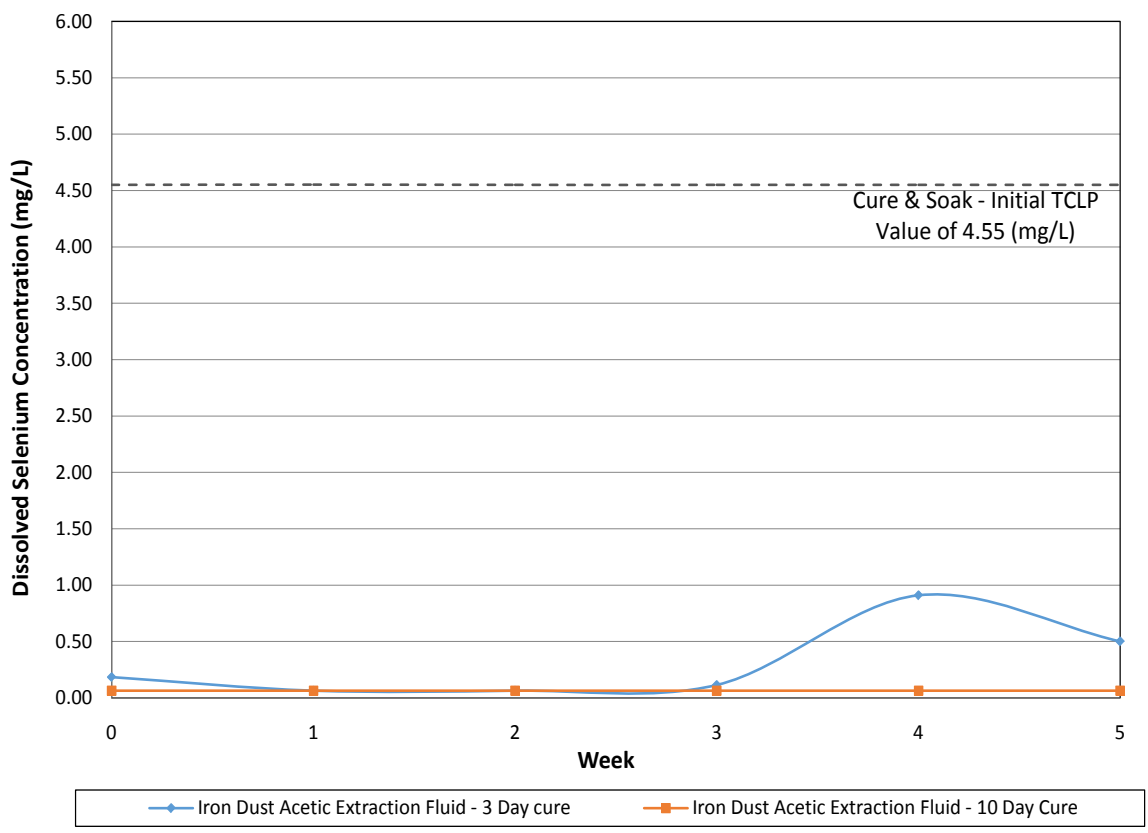

Figure 5. Selenium TCLP concentrations after extended extraction time. 


\subsection{Assessment of Zero Valent Selenium (ZVS) Permanence in the Absence of Iron in TCLP Test Solution}

The permanence of treatment considers the stability of selenium chemically reduced to a zero-valent state. To evaluate permanence a simulated BHD was prepared using a mixture of zero valent selenium (ZVS) and silicon dioxide $\left(\mathrm{SiO}_{2}\right)$ powder, to represent inert components of BHD. No iron was utilized to represent complete iron removal from the treated BHD (through reaction, solubilization, and mobilization via landfill percolation). Although contact (i.e., close proximity) between the ZVI and selenium are required for surface electron transfer, there is no support that proximity is required to maintain a reduced chemical state. ZVS has a solubility of $0.24 \mu \mathrm{g} / \mathrm{L}$ and has reduced potential to solubilize without chemical oxidation [15].

Prior to blending with the $\mathrm{SiO}_{2}$ powder, ZVS was triple washed with DI water to remove ionic (oxidized) selenium from the surface. The triple washed ZVS was combined with the $\mathrm{SiO}_{2}$ powder in mass concentration of $0.125 \mathrm{~g} \mathrm{ZVS}$ and $99.875 \mathrm{~g} \mathrm{SiO}_{2}$ powder. The bases of using this ratio was that a total selenium concentration of $0.125 \mathrm{~g}$ selenium per $100 \mathrm{~g}$ of actual BHD corresponded to a selenium TCLP of $8 \mathrm{mg} / \mathrm{L}$, which is the maximum TCLP concentration considered in this testing.

Results from the external laboratory and internal extraction testing are provided as Table 1 .

\subsection{Quantification of Selenium in Baghouse Dust (BHD)}

Testing was conducted on BHD material to estimate the speciation of present in the as-received material Samples of raw, un-stabilized BHD and stabilized BHD were analyzed in triplicate (Table 2). The total quantity and speciation of selenium has been estimated using a subtractive method. Using this method, TCLP tests were performed on BHD samples before and after stabilization methods, and compared to Total Selenium results from historical data from the manufacture.

Table 1. Zero Valent Selenium in the absence of iron: TCLP stability testing.

\begin{tabular}{|c|c|c|c|c|c|}
\hline \multicolumn{3}{|c|}{ External Laboratory Extraction Testing } & \multicolumn{3}{|c|}{ In-House Extraction Testing } \\
\hline Description & Result & Units & Description & Result & Units \\
\hline $\begin{array}{c}99.875 \mathrm{~g} \text { Simulated BHD } \\
+0.125 \mathrm{~g} \text { ZVS }\end{array}$ & $<0.05$ & $\mathrm{mg} / \mathrm{L}$ & $\begin{array}{c}99.875 \mathrm{~g} \text { Simulated BHD } \\
+0.125 \mathrm{~g} \text { ZVS in } 2 \mathrm{~L} \text { of } \\
\text { Acetic Extraction Fluid }\end{array}$ & 0.0060 & $\mathrm{mg} / \mathrm{L}$ \\
\hline- & - & - & $\begin{array}{l}99.875 \mathrm{~g} \text { Simulated BHD } \\
+0.125 \mathrm{~g} \mathrm{ZVS} \text { in } 800 \mathrm{~mL} \\
\text { of Acetic Extraction Fluid }\end{array}$ & 0.0068 & $\mathrm{mg} / \mathrm{L}$ \\
\hline $\begin{array}{c}99.625 \mathrm{~g} \text { Simulated BHD } \\
+0.375 \mathrm{~g} \text { ZVS }\end{array}$ & $<0.05$ & $\mathrm{mg} / \mathrm{L}$ & - & - & - \\
\hline $\begin{array}{c}98.9 \mathrm{~g} \text { Simulated BHD + } \\
1.1 \mathrm{~g} \mathrm{ZVS}\end{array}$ & $<0.05$ & $\mathrm{mg} / \mathrm{L}$ & - & - & - \\
\hline
\end{tabular}


Table 2. Total Selenium Results.

\begin{tabular}{cccc}
\hline & $\begin{array}{c}\text { Total Selenium } \\
\text { Results }(\mathrm{mg} / \mathrm{kg})\end{array}$ & $\begin{array}{c}\text { Selenium TCLP } \\
\text { Results }(\mathrm{mg} / \mathrm{L})\end{array}$ & $\begin{array}{c}\text { Leachable Selenium } \\
\text { (rule of 20 adjustment) } \\
(\mathrm{mg} / \mathrm{kg})\end{array}$ \\
\hline Before Treatment & 105 & 3.37 & 67.4 \\
& 106 & 3.37 & 67.4 \\
& 91.6 & 3.42 & 68.4 \\
Average: 100.9 & Average: 3.38 & Average: 67.73 \\
\hline 97.4 & 0.324 & 6.48 \\
& 99.9 & 0.236 & 4.72 \\
& 95.6 & 0.09 & 1.8 \\
& Average: 97.6 & Average: 0.22 & Average: 4.07 \\
\hline
\end{tabular}

Total Selenium testing used a digestion of the solid BHD assay to solubilize and oxidize selenium contained within the BHD material (EPA Method 6010C). Therefore, total selenium results provide a good representation of all selenium, both ionic and ZVS.

However, it is recognized that some selenium may be so tightly bound in the complex matrix of the BHD that it is not liberated even by the aggressive extraction method used for total selenium testing. As a secondary test of total selenium analysis, three samples of the as-received BHD were subjected to microwave assisted nitric acid digestion and tested for total selenium using ICP/EAS per EPA Method 6010C.

The average total selenium result using conventional EPA digestion protocol was $100.9 \mathrm{mg} / \mathrm{kg}$ versus $106 \mathrm{mg} / \mathrm{kg}$ using the aggressive digestion technique. The results suggest that the more aggressive digestion provided nominally differences and support that total selenium in the BHD quantified analytically using EPA Method 6010C is acceptable.

In contrast, the TCLP extraction procedure utilized acidic, buffered DI water. Based on physical chemical properties, ionic selenium is leachable by the TCLP method, while ZVS is not. Therefore, the difference between the results of total selenium testing and TCLP testing of BHD can be used to determine the amount of selenium in zero valent form in stabilized solids.

\subsection{Proposed Mechanism of Treatment and Stabilization}

Figure 6 depicts the proposed model of reduction and fate of selenium within the BHD matrix. The BHD may contain both ionic and zero valent selenium $\left(\mathrm{Se}^{0}\right)$, denoted as $\mathrm{A}$ and $\mathrm{B}$ respectively. During treatment, water and ZVI are added to the BHD in the proper ratios and agitated to solubilize selenium and allow contact between the selenium and ZVI. The mixture is allowed to cure for 10 days to provide additional reaction time and stabilization. In this process, a large fraction of the ionic selenium $(A)$ is converted to elemental selenium $\left(\mathrm{A}_{2}\right)$. 


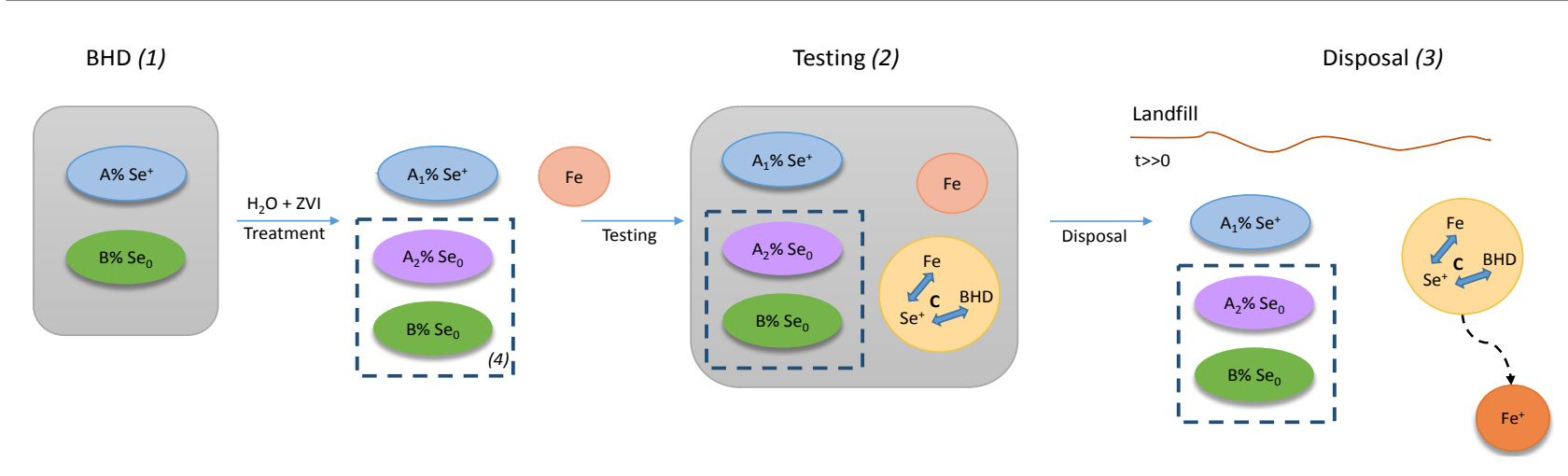

Figure 6. Selenium fate schematic. (1) Where $A=A_{1}+A_{2}$. B does not participate in Treatment. (2) Where: $C$ is a minor, physically bound fraction of $\mathrm{Se}^{+}, C \ll \mathrm{A}_{1}+\mathrm{A}_{2}+\mathrm{B} \ll \mathrm{B}+\mathrm{A}_{2}$. Mixture passes the TCLP test. (3) Presence of Fe is not required to maintain zero-valent state of $A_{1}$ and $B$. As Fe dissociates, $C$ may become leachable; though $C \ll A_{1}+A_{2}+B$. (4) The dashed box represents selenium that was converted to or already existing as the zero-valent species.

Using a TCLP leaching procedure, ionic selenium $\left(\mathrm{A}_{1}\right)$ is obtained through analysis. The physically bound and converted selenium (C) remains as a solid. The quantity $(C)$ is assumed to be a summation of $B+A_{2}$. Other forms of selenium containing compounds may be contained within the matrix. ZVI may be oxidized to $\mathrm{Fe}(\mathrm{II})$ or $\mathrm{Fe}(\mathrm{III})$ and form ferric hydroxide in solution (Ling, 2015). Thus, the formation of FeSe or selenite adsorbed to ferric hydroxide may occur.

The data presented in Table 2 show that approximately $70 \%$ of the untreated $\mathrm{BHD}$ is ionic selenium and $30 \%$ of the selenium is ZVS. The treatment process results in conversion of greater than $90 \%$ of the ionic selenium to ZVS resulting in about a $96 \%$ concentration of ZVS in the treated BHD. The observed difference in total selenium before and after stabilization of approximately $3 \%$ may be attributed to selenium which is locked into the solid matrix of the BHD as a result of curing. This bound selenium may be physically occluded from the sample digestion method, and incrementally further reduces leachable selenium.

When the stabilized BHD is disposed of in a landfill, selenium which has been converted to ZVS will remain in landfill environmental conditions after the remaining iron, which does not participate in the initial redox reaction, oxidizes (dissipates or washes away).

Figure 7 shows a potential mass balance of selenium within the landfill using data obtained during this study. If the bound selenium is fully leached, the TCLP result would be increased by about $0.165 \mathrm{mg} / \mathrm{L}$, but would remain well below the TCLP limit of $1.0 \mathrm{mg} / \mathrm{L}$. Furthermore, selenium that is potentially adsorbed to the surface of BHD or iron accounts for less than $3 \%(3 \mathrm{mg} / \mathrm{kg})$ of the total quantity of selenium of BHD (Table 2). Using the 20:1 rule, if this mass were to completely leach, the corresponding concentration would be $0.15 \mathrm{mg} / \mathrm{L}$ (EPA Method 1311).

The resulting TCLP concentration $(\mathrm{A} 1=0.22 \mathrm{mg} / \mathrm{L})$ represents the value measured upon disposal after stabilization. Should the remaining selenium which is physically bound $(\mathrm{C}=0.165)$ the total leached concentration from the stabilized product would be $0.39 \mathrm{mg} / \mathrm{L}$, which is below the $1 \mathrm{mg} / \mathrm{L}$ TCLP hazardous waste value. 
Disposal

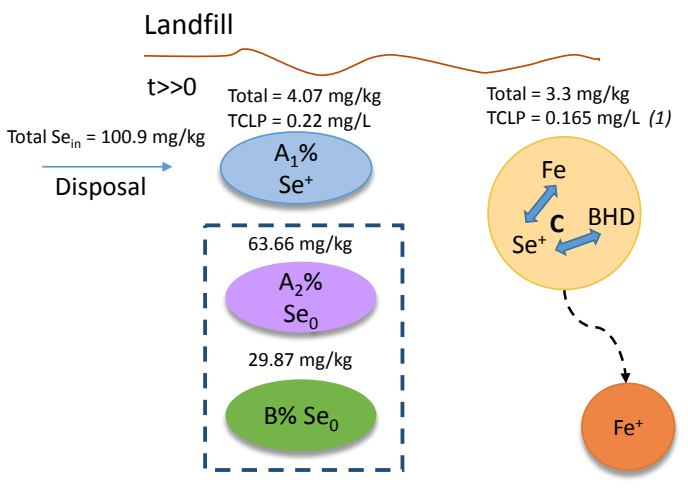

Figure 7. Selenium mass balance. Note that the dashed box represents selenium that was converted to or already existing as the zero-valent species. (1) This value was calculated based on the total measurements.

\section{Conclusions}

The testing performed identified a mixture of $4 \%$ ZVI by BHD mass and $35 \%$ water (as a percentage of total dry mass) as the optimum condition. Since this is an aqueous-mediated solid interface reaction, both the quantity of water to mobilize the selenium and the surface area of ZVI are critical parameters. The testing results demonstrated that the selenium conversion increased with increasing surface area and reached asymptotic values with particle sizes smaller than 80 mesh for production-grade material.

This study demonstrated that ZVI converts ionic selenium to a zero-valent state in BHD. Although it is recognized that a small fraction of ionic selenium fails to react with the iron dust (ZVI), repeated testing has shown that despite the presence of the unreacted ionic selenium, the TCLP results following treatment do not exceed the $1 \mathrm{mg} / \mathrm{L}$ threshold. In real BHD, no additional release of selenium was observed subsequently to iron being solubilized. Additional testing using "simulated BHD" with stock zero-valent selenium (ZVS) showed a de minimus amount of re-solubilization, supporting chemical stability in a landfill environment. Therefore, since ZVS is chemically equivalent, whether in simulated or real samples, the treatment appears to be effective and permanent.

Furthermore, this study allows for the conversion and treatment of selenium in BHD in a controlled, engineered reaction prior to disposal and supports that the material would comply with permissible dilution constraints as defined by the USEPA.

\section{References}

[1] Chapman, P.M., Adams, W.J., Brooks, M., Delos, C.G., Luoma, S.N., Maher, W.A., Ohlendorf, H.M., Presser, T.S. and Shaw, P. (2010) Ecological Assessment of Selenium in the Aquatic Environment. CRC Press, Boca Raton. https://doi.org/10.1201/EBK1439826775

[2] Hill, C. (2010) Review of Available Technologies for the Removal of Selenium from Water. Final Report, prepared for North American Metals Council (NAMC). 
[3] Tan, L.C., Nancharaiah, Y.V., van Hullebusch, E.D. and Lens, P.N. (2016) Selenium: Environmental Significance, Pollution, and Biological Treatment Technologies. Biotechnol. Adv., 34, 886-907. https://doi.org/10.1016/j.biotechadv.2016.05.005

[4] Chappell, M.A., Seiter, J.M., Bednar, A.J., Price, C.L., Averett, D., Lafferty, B., Tappero, R., Stanley, J.S., Kennedy, A.J. and Steevens, J.A. (2014) Stability of Solid-Phase Selenium Species in Fly Ash after Prolonged Submersion in a Natural River System. Chemosphere, 95, 174-181. https://doi.org/10.1016/j.chemosphere.2013.08.061

[5] US Department of Health and Human Services (2003) Toxicological Profile for Selenium. US Department of Health and Human Services, Public Health Service, Atlanta, GA.

[6] U.S. Environmental Protection Agency (1998) 40 CFR 268.3 Dilution Prohibited as a Substrate for Treatment.

[7] Zhang, Y., Amrhein, C., Chang, A. and Frankenberger, W.T. (2008) Effect of Zero-Valent Iron and a Redox Mediator on Removal of Selenium in Agricultural Drainage Water. Science of The Total Environment, 407, 89-96.

https://doi.org/10.1016/j.scitotenv.2008.09.009

[8] Merrill, D., Manzione, M., Peterson, J., Parker, D., Chow, W. and Hobbs, A. (1986) Field Evaluation of Arsenic and Selnium Removal by Iron Coprecipitation. Journal ( Water Pollution Control Federation), 18-26.

[9] Yoon, I., Kim, K., Bang, S. and Kim, M.G. (2011) Reduction and Adsorption Mechanisms of Selenate by Zero-Valent Iron and Related Iron Corrosion. Applied Catalysis B: Environmental, 104, 185-192. https://doi.org/10.1016/j.apcatb.2011.02.014

[10] Qiu, S., Lai, H., Roberson, M., Hunt, M., Amrhein, C., Giancarlo, L., Flynn, G. and Yarmoff, J. (2000) Removal of Contaminants from Aqueous Solution by Reaction with Iron Surfaces. Langmuir, 16, 2230-2236. https://doi.org/10.1021/la990902h

[11] Séby, F., Potin-Gautier, M., Giffaut, E., Borge, G. and Donard, O.F.X. (2001) A Critical Review of Thermodynamic Data for Selenium Species at $25^{\circ} \mathrm{C}$. Chemical Geology, 171, 173-194. https://doi.org/10.1016/S0009-2541(00)00246-1

[12] Ling, L., Pan, B. and Zhang, W. (2015) Removal of Selenium from Water with Nanoscale Zero-Valent Iron: Mechanisms of Intraparticle Reduction of Se (IV). Water Research, 71, 274-281. https://doi.org/10.1016/j.watres.2015.01.002

[13] Regadío, M., Ruiz, A., De Soto, I., Rodriguez Rastrero, M., Sánchez, N., Gismera, M., Sevilla, M., da Silva, P., Rodríguez Procopio, J. and Cuevas, J. (2012) Pollution Profiles and Physicochemical Parameters in Old Uncontrolled Landfills. Waste Management, 32, 482-497. https://doi.org/10.1016/j.wasman.2011.11.008

[14] Masscheleyn, P.H., Delaune, R.D. and Patrick Jr., W.H. (1990) Transformations of Selenium as Affected by Sediment Oxidation-Reduction Potential and pH. Environmental Science \& Technology, 24, 91-96. https://doi.org/10.1021/es00071a010

[15] Bruggeman, C., Maes, A., Vancluysen, J. and Vandemussele, P. (2005) Selenite Reduction in Boom Clay: Effect of FeS2, Clay Minerals and Dissolved Organic Matter. Environmental Pollution, 137, 209-221.

https://doi.org/10.1016/j.envpol.2005.02.010 
Submit or recommend next manuscript to SCIRP and we will provide best service for you:

Accepting pre-submission inquiries through Email, Facebook, LinkedIn, Twitter, etc. A wide selection of journals (inclusive of 9 subjects, more than 200 journals)

Providing 24-hour high-quality service

User-friendly online submission system

Fair and swift peer-review system

Efficient typesetting and proofreading procedure

Display of the result of downloads and visits, as well as the number of cited articles Maximum dissemination of your research work

Submit your manuscript at: http://papersubmission.scirp.org/

Or contact jep@scirp.org 